\title{
Changes of HRQoL in Patients of Pulmonary TB at Different Phases of Category-1 Anti-tubercular Chemotherapy
}

\author{
Dr. Md. Nazmul Hasan ${ }^{1 *}$, Dr. Mohammed Mostanshir Billah², Dr. Md. Abdur Rahim³, Dr. Imtiaz Ahmed ${ }^{4}$, Dr. Md. Tariq
} Hasan $^{5}$

\footnotetext{
${ }^{1}$ Assistant Professor, Dept. of Internal Medicine, Bangabandhu Sheikh Mujib Medical University, Dhaka, Bangladesh

${ }^{2}$ Medical Officer, OSD, Directorate General of Health Services, Mohakhali, Dhaka, Bangladesh

${ }^{3}$ Professor, Department of Internal Medicine, Bangabandhu Sheikh Mujib Medical University, Dhaka, Bangladesh

${ }^{4}$ Assistant Professor, Dept of Medicine, Sir Salimullah Medical College, Mitford, Dhaka, Bangladesh

${ }^{5} \mathrm{MD}$ (Resident), Phase-B, Dept. of Oncology, Bangabandhu Sheikh Mujib Medical University, Dhaka, Bangladesh
}

DOI: $10.36347 /$ sjams.2020.v08i07.004

| Received: 15.06.2020 | Accepted: 22.06.2020 | Published: 04.07.2020

*Corresponding author: Dr. Md. Nazmul Hasan

Background: Tuberculosis (TB) is the second common cause of death worldwide. Bangladesh is one of the high prevalent regions for tuberculosis. Tuberculosis significantly affects the quality of life of a patient. It not only affects the physical health but also alters the other domains like psychological aspect of health. Objective: In this study our main goal is to find out changes of HRQoL in patients of pulmonary TB at different phases of category-1 antitubercular treatment. Method: This cross-sectional study was conducted in Department of Internal Medicine, BSMMU, Dhaka from September, 2015 to September, 2016. About 61, respondents were included in the study. The HRQoL is assessed by SF-36 questionnaire which is already validated in Bengali beforehand. Results: Among 61 patients, the average age of PTB patients mean $( \pm$ SD) was $(31 \pm 11.4)$ with a male preponderance. The improvement of HRQoL was significant $(\mathrm{p}<0.001)$ and continued till the end of treatment after six months. Comparison of the scores in patient before starting treatment and after the initial phase (first 2 months) of treatment shows significant improvement in all health domains $(\mathrm{p}<0.001)$. Also, there is a significant difference of HRQoL score between pulmonary tuberculosis patient at two months of treatment and completion of anti-tubercular chemotherapy $(\mathrm{p}<0.001)$. Conclusion: This study observed that HRQoL improves significantly with DOTS-based anti-tubercular treatment. Therefore, quality of life in addition to chemotherapy should be taken into account in case of tuberculosis treatment.

Keywords: Health related quality of life (HRQoL), tuberculosis (TB), anti-tubercular treatment.

Copyright @ 2020: This is an open-access article distributed under the terms of the Creative Commons Attribution license which permits unrestricted use, distribution, and reproduction in any medium for non-commercial use (NonCommercial, or CC-BY-NC) provided the original author and source are credited.

\section{INTRODUCTION}

Tuberculosis (TB) is the most common infectious disease worldwide and second common cause of death. TB not only affects the patient's physical health, but also social, economic and physiological wellbeing. A comprehensive assessment of patients with tuberculosis is necessary to understand the disease impact and to evaluate the strength of the treatment programme and this can be made by measuring patient's quality of life[1].

Till to date, little attention has been paid to the impact of TB and its treatment on health-related quality of life (HRQoL) of patients. As Bangladesh is a TB prone country and there is lack of previous studies on HRQoL in TB patients in our country. There are several methods for evaluating health status and disease management evaluation. The assessment of patient reported outcomes is a valuable method for this purpose and the quality of life (QOL) instruments have been developed to measure patients' outcome in clinical research and practice [2].

WHO proposed the definition of HRQoL, an 'individuals' perception of their position in life in the context of the culture and value systems in which they live and in relation to their goals, expectations, standards and concerns [3].

In this study our main goal is to find out changes of HRQoL in patients of pulmonary TB at different phases of anti-tubercular treatment.

\section{Methodology}

Types of study

- It was a cross sectionalstudy. 


\section{Place and period of the study}

- The study was conducted in Department of Internal Medicine, BSMMU, and Dhaka from September, 2015 to March, 2017.

\section{Sample size and population}

- About 61 patients who were diagnosed to have smeared positive pulmonary tuberculosis and registered for anti-TB treatment at inpatient and out-patient department of Internal Medicine were included in the study.

\section{Sampling technique}

- Purposive Sampling.

\section{Data Collection Method}

- All participants were signed an informed consent before entering into the study. Before study enrolment, all individuals were informed about the voluntary nature of participation and confidentiality as well as the use of their data for research purposes only. Also, the confidentiality of the participants' data was ensured by the lack of any identifying personal information. The diagnosis of PTB was made through relevant history (fever, cough for 3 weeks or more and weight loss), clinical examination and bacteriological confirmation by sputum for acid fast bacilli (AFB).

\section{Data AnAlysis}

- After data collection responses of the responded were analyzed following general guideline for SF-36 scoring instructions. Statistical Package for Social Science (SPSS) version 22 was used for statistical analysis. Data was presented as mean \pm standard deviation (SD) for quantitative variables and frequency and percentages for qualitative variables. Paired sample T-test was done for comparing QOL of TB patients at different time points. All collected data were checked and verified thoroughly to reduce inconsistency and for omission and improbabilities.

\section{RESULTS}

In this cross sectional study, among 61 patient, the mean $( \pm \mathrm{SD})$ age of PTB patients was $(31 \pm 11.4)$. Male respondents were more $(54 \%)$ than females. About thirty nine percent of the participants were indulged in smoking while $61 \%$ were nonsmoker (Table-I).

Table-I: Demographic characteristics of case and control groups $(n=61)$

\begin{tabular}{|c|c|c|}
\hline Demographic characteristics $(\mathrm{N}=61)$ & Number of PTB patient(n) & Frequency in percentage $(\%)$ \\
\hline \multicolumn{3}{|l|}{ Age $(\text { yrs })^{*}$} \\
\hline$<20$ & 7 & $(11.5)$ \\
\hline $20-29$ & 29 & $(47.5)$ \\
\hline $30-39$ & 11 & $(18.0)$ \\
\hline $40-49$ & 7 & $(11.5)$ \\
\hline $40-59$ & 5 & $(8.2)$ \\
\hline$\geq 60$ & 2 & $(3.3)$ \\
\hline Mean $\pm \mathrm{SD}^{\#}$ & \multicolumn{2}{|l|}{$31 \pm 11.4$} \\
\hline \multicolumn{3}{|l|}{ Gender* } \\
\hline Male & 36 & $(59.0)$ \\
\hline Female & 25 & $(40.9)$ \\
\hline \multicolumn{3}{|l|}{ Socio-economic condition ${ }^{*}$} \\
\hline Low $(<10,000)$ & 37 & $(60.7)$ \\
\hline Middle $(10,001-30,000)$ & 23 & $(37.7)$ \\
\hline High $(>30,000)$ & 1 & $(1.6)$ \\
\hline Smoker & 24 & $(39.3)$ \\
\hline Non smoker & 37 & $(60.7)$ \\
\hline
\end{tabular}

Figures in the parentheses indicate corresponding \%;

*Chi-squared Test $\left(\chi^{2}\right)$ was done to analyze the data

\#Data was analyzed using unpaired t-Test and was presented as mean $\pm \mathrm{SD}$.

In figure-1 shows number of symptoms among cases $(n=61)$. Where most of the patients $(72.1 \%)$ presented with three or more symptoms, while in 17 cases $(27.9 \%)$ there were fewer than 3 symptoms. The patient having more than three or more symptoms have lower QoL than who have less than three symptoms $(\mathrm{p}<0.05)$. 


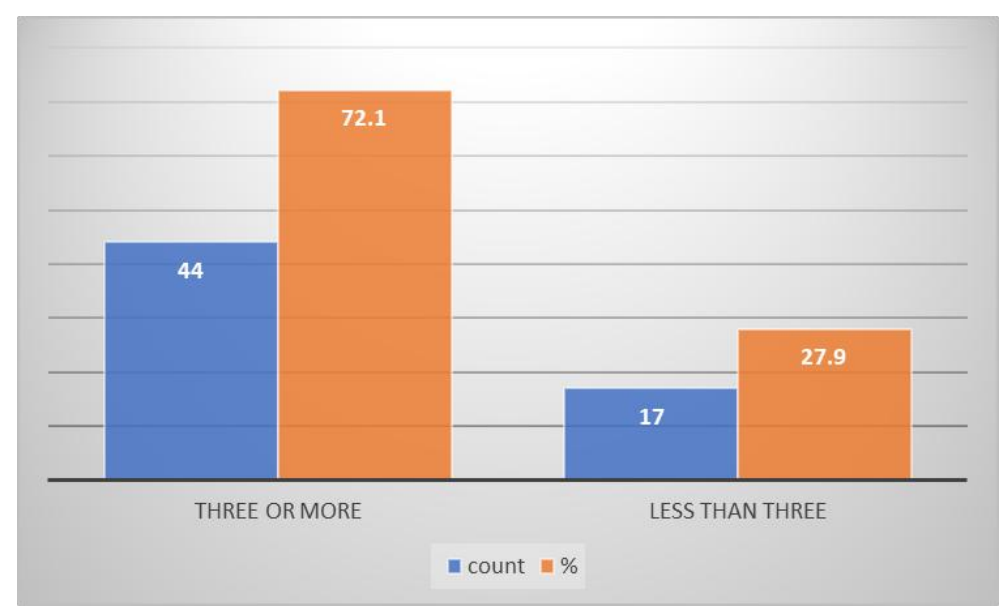

Fig-1: Number of symptoms among cases $(n=61)$

In table-2 shows average Values of SF 36 Domains scores at different time points of treatment. Paired $\mathrm{T}$ test was done to show changes in HRQoL scores at different time points of treatment. HRQoL improved mostly within first two months of treatment and it continued till the end of treatment. Data were presented as Mean $\pm \mathrm{SD}$. The following table is given below in detail:

Table-2: Average Values of SF 36 Domains scores at different time points of treatment $(n=61)$

\begin{tabular}{|l|l|l|l|}
\hline SF 36 Domain & $\begin{array}{l}\text { Before treatment } \\
\text { Mean } \pm \text { SD }\end{array}$ & $\begin{array}{l}\text { After 2 months treatment } \\
\text { Mean } \pm \text { SD }\end{array}$ & $\begin{array}{l}\text { After 6 months treatment } \\
\text { Mean } \pm \text { SD }\end{array}$ \\
\hline Physical Functioning (PF) & $52.62 \pm 7.50$ & $72.54 \pm 6.30$ & $75.49 \pm 4.80$ \\
\hline Role Physical (RP) & $46.96 \pm 19.96$ & $65.16 \pm 16.63$ & $75.40 \pm 16.76$ \\
\hline Bodily Pain (BP) & $45.57 \pm 12.39$ & $63.97 \pm 8.28$ & $67.66 \pm 6.71$ \\
\hline General Health (GH) & $37.86 \pm 9.46$ & $52.20 \pm 7.03$ & $55.32 \pm 5.77$ \\
\hline Vitality (VT) & $41.55 \pm 5.66$ & $58.36 \pm 5.22$ & $60.24 \pm 5.73$ \\
\hline Social Functioning (SF) & $53.07 \pm 8.73$ & $64.13 \pm 9.48$ & $66.39 \pm 7.33$ \\
\hline Role Emotion (RE) & $51.49 \pm 20.21$ & $69.11 \pm 10.36$ & $70.07 \pm 11.72$ \\
\hline Mental Health (MH) & $46.09 \pm 6.55$ & $55.31 \pm 5.62$ & $57.85 \pm 5.01$ \\
\hline
\end{tabular}

In table- 3 shows changes in average Values of SF 36 Domains scores before treatment and after 2 months of treatment $(n=61)$. Comparison of the scores in cases before or within two weeks of starting treatment and after the initial phase of treatment shows significant improvement in all health domains after two months of treatment $(\mathrm{p}<0.01)$. Paired $\mathrm{T}$ test was done to analyze the data and were presented as Mean $\pm \mathrm{SD}$. The following table is given below in detail:

Table-3: Changes in Average Values of SF 36 Domains scores before treatment and after 2 months of treatment $(\mathbf{n}=61)$

\begin{tabular}{|l|l|l|l|}
\hline SF 36 Domain & $\begin{array}{l}\text { Before starting of treatment } \\
\text { Mean( }(\mathbf{S D})\end{array}$ & $\begin{array}{l}\text { After initial phase(2 months) treatment } \\
\text { Mean( } \mathbf{( S D )}\end{array}$ & P value \\
\hline Physical Functioning (PF) & $52.62 \pm 7.50$ & $72.54 \pm 6.30$ & $<0.001$ \\
\hline Role Physical (RP) & $46.96 \pm 19.96$ & $65.16 \pm 16.63$ & $<0.001$ \\
\hline Bodily Pain (BP) & $45.57 \pm 12.39$ & $63.97 \pm 8.28$ & $<0.001$ \\
\hline General Health (GH) & $37.86 \pm 9.46$ & $52.20 \pm 7.03$ & $<0.001$ \\
\hline Vitality (VT) & $41.55 \pm 5.66$ & $58.36 \pm 5.22$ & $<0.001$ \\
\hline Social Functioning (SF) & $53.07 \pm 8.73$ & $64.13 \pm 9.48$ & $<0.001$ \\
\hline Role Emotion (RE) & $51.49 \pm 20.21$ & $69.11 \pm 10.36$ & $<0.001$ \\
\hline Mental Health (MH) & $46.09 \pm 6.55$ & $55.31 \pm 5.62$ & $<0.001$ \\
\hline
\end{tabular}

In table-4 shows changes in average values of SF 36 domains after initial treatment and after 6 months of treatment $(n=61)$. Paired $T$ test showed significant improvement in all domains after six months of treatment than that of initial phase of treatment $(\mathrm{p}<$ 0.01 ). Data are presented as Mean \pm SD. The following table is given below in detail: 
Table-4: Changes in average values of SF 36 domains after initial treatment and after 6 months of treatment $(\mathbf{n}=61)$

\begin{tabular}{|l|l|l|l|}
\hline SF 36 Domain & $\begin{array}{l}\text { After initial phase(2 months) } \\
\text { treatment }\end{array}$ & SF 36 Domain & $\begin{array}{l}\text { After initial phase(2 months) } \\
\text { treatment }\end{array}$ \\
\hline Physical Functioning (PF) & $72.54 \pm 6.30$ & $75.49 \pm 4.80$ & $<0.001$ \\
\hline Role Physical (RP) & $65.16 \pm 16.63$ & $75.40 \pm 16.76$ & $<0.001$ \\
\hline Bodily Pain (BP) & $63.97 \pm 8.28$ & $67.66 \pm 6.71$ & $<0.001$ \\
\hline General Health (GH) & $52.20 \pm 7.03$ & $55.32 \pm 5.77$ & $<0.001$ \\
\hline Vitality (VT) & $58.36 \pm 5.22$ & $60.24 \pm 5.73$ & $<0.001$ \\
\hline Social Functioning (SF) & $64.13 \pm 9.48$ & $66.39 \pm 7.33$ & $<0.001$ \\
\hline Role Emotion (RE) & $69.11 \pm 10.36$ & $70.07 \pm 11.72$ & $<0.001$ \\
\hline Mental Health (MH) & $55.31 \pm 5.62$ & $57.85 \pm 5.01$ & $<0.001$ \\
\hline
\end{tabular}

\section{Discussion}

In this cross sectional study, among 61 patients, the mean $( \pm \mathrm{SD})$ age of PTB patients was $(31 \pm 11.4)$. There was male preponderance. About one third of patient was smoker. Most of the cases (72.1\%) had three or more symptoms and their QoL scores were lower compared to the patients presented with less than three symptoms. One study conducted in Malaysia showed similar findings [4].

The QoL of TB patients was assessed at twomonths as well as at six-months of treatment with fourdrug TB regimens. Overall, QoL score increased in all domains of questionnaire progressively at two and six months after anti-tubercular treatment. The QoL of TB patients was significantly improved at two months and at six months of treatment. And there was statistical difference between the second and sixth months of TB treatment. The results showed that the QoL was significantly and rapidly increased after two months which indicated the positive impact of the four-drug TB regimens on the improvement of the QoL in these patients. Significant improvement in the continuation phase indicates though most of the improvement occurs within two months of treatment, it continues throughout the treatment period. A similar trend in the improvement of HRQoL scores in association with TB treatment was reported in different studies [5-7]. However, a study conducted on 102 TB patients where there was an initial decline in role-physical, vitality and mental health followed by rapid rise [8].

The reason for the low QoL may be related to psychological outcome of the disease due to isolation from the community and family life based on the contagious nature of TB infection, which also may lead to depression among TB patients. A study in Pakistan was carried out on 60 TB patients and showed that $80 \%$ of them were depressed. The study concluded this high rate of depression among TB patients was due to lower socioeconomic status, long treatment period, stigmatic nature of the disease, as well as fear and threat concerning the risk of transmitting infection from airborne bacteria which all lead to decrease in resistance against the infection and response to the treatment which was followed by isolation and disappointment of the patient [9].

Also, the differences in patients' HRQoL levels among the studies might be either due to inconsistency in patients' characteristics, differences in cultures and mode of data collection related to HRQoL, or attributable to variation in the NTP's performance. With respect to patients' HRQoL at the end of TB treatment, the findings of the current study were in accordance with most of the earlier studies in the same area.

There are some limitations of the study such as low sample size, no control group in the study and there might be recall bias.

\section{Conclusion}

In summary, HRQoL is improved rapidly and significantly with DOTS-based category-1 antitubercular treatment. Therefore, attention should also be focused on QoL in addition to drug treatment of tuberculosis.

\section{REFERENCES}

1. Bowling A. 'measuring disease: A review of disease specific quality of life measurement scales', Milton Keynes: Open University Press. 1995; 30: 1-3.

2. Bottomley A, Flechtner H, Efficace F, Vanvoorden V, Coens C, Therasse P, Velikova G, Blazeby J, Greimel E. Health related quality of life outcomes in cancer clinical trials. European Journal of Cancer. 2005 Aug 1;41(12):1697-709.

3. Whoqol Group. The World Health Organization quality of life assessment (WHOQOL): position paper from the World Health Organization. Social science \& medicine. 1995 Nov 1;41(10):1403-9.

4. Norman GR, Sloan JA, Wyrwich KW. Interpretation of changes in health-related quality of life: the remarkable universality of half a standard deviation. Medical care. 2003 May 1:58292.

5. Perkins JJ, Sanson-Fisher RW. An examination of self-and telephone-administered modes of 
administration for the Australian SF-36. Journal of clinical epidemiology. 1998 Nov 1;51(11):969-73.

6. Peng J. Symptomatic survey on pulmonary tuberculosis in Shanghai rural areas. Zhonghua jie he he hu xi za zhi= Zhonghua jiehe he huxi zazhi= Chinese journal of tuberculosis and respiratory diseases. 1993 Feb;16(2):83-4.

7. Peng J. Symptomatic survey on pulmonary tuberculosis in Shanghai rural areas. Zhonghua jie he he hu xi za zhi= Zhonghua jiehe he huxi zazhi= Chinese journal of tuberculosis and respiratory diseases. 1993 Feb;16(2):83-4.
8. Peterson Tulsky J, Castle White M, Young JA, Meakin R, Moss AR. Street talk: knowledge and attitudes about tuberculosis and tuberculosis control among homeless adults. The International Journal of Tuberculosis and Lung Disease. 1999 Jun 1;3(6):528-33.

9. Rundi C. Understanding tuberculosis: perspectives and experiences of the people of Sabah, East Malaysia. Journal of health, population, and nutrition. 2010 Apr;28(2):114. 